\title{
How changes in market conditions affect screening activity, credit risk, and the lending behaviour of banks
}

\author{
Nikolaos I. Papanikolaou* \\ Bournemouth University, Faculty of Management, Business School \\ Department of Accounting, Finance \& Economics \\ 89 Holdenhurst Road, Bournemouth, BH8 8EB, United Kingdom
}

\begin{abstract}
The global financial crisis dramatically transformed the market conditions in the banking industry. We construct a theoretical model of spatial competition that considers the differential information between lenders and loan applicants to explore how changes in the market structure affect the lending behaviour of banks and their incentives to invest in screening and how this, in turn, affects the level of credit risk in the economy. Our findings reveal that enhanced competition reduces lending cost thus encouraging the entry of new customers in credit markets. Also, that the transportation cost that loan applicants are required to pay to reach the bank of their interest shrinks with respect to the degree of competition. We further lend support to the view that stiffer competition has an increasing impact on the level of credit risk. Notably, we find that competition strengthens the incentives of banks to engage in screening activity and that screening serves as a protection mechanism that can provide banks with a shield against bad loans. Overall, when market conditions are substantially distorted, this has a dilutive impact on the incentives mechanism of banks to screen their applicants. We provide empirical evidence which is consistent with the conceptual underpinnings of our theoretical model and the obtained findings.
\end{abstract}

Keywords: banking; market structure; spatial competition; screening; credit risk; financial crisis

JEL classifications: D01; D40; D52; D82; G21

${ }^{*}$ Contact details: Tel.: +44 (0) 1202 968769; E-mail: npapanikolaou@ @ournemouth.ac.uk 


\section{Introduction}

One of the key tasks of banks is to mitigate the informational asymmetries, which are inherent in the operation of credit markets. To alleviate this friction, banks conduct credit evaluations which rely on the gathering and processing of information about the particular characteristics of wouldbe borrowers, a technique that is known as 'screening'. The more information a bank collects and the higher the quality of this information, the more efficient it is for the bank to screen out bad applications successfully and, hence, to reduce the amount of risk in its loan portfolio.

The late-2000s financial crisis dramatically transformed the conditions in banking markets around the globe. A new landscape has been formed due to the numerous mergers and acquisitions which occurred in the wake of the crisis. Additionally, many troubled financial institutions either went bankrupt under the auspices of regulatory authorities, or received assistance in the form of bailouts, which further fed the transformation of banking markets. As Soedarmono et al. (2013) point out, financial crises spawn several reforms such as recapitalisations, consolidations, or assisted failures, which substantially alter the degree of competition. Similarly, Williams and Nguyen (2005) highlight that a period that follows a financial crisis is characterised by considerable changes in the structure of the affected banking markets due to the restructuring programmes that authorities launch.

In view of these profound changes, the link between market structure, banks' incentives to screen loan applicants, and credit risk is once again at the forefront of policy debates. However, only a handful of studies have attempted to examine this relationship in the aftermath of the crisis. Interestingly, there is as yet no academic consensus on whether competition results in higher or lower screening levels or whether it leads to increased or decreased risk. We contribute to and extend the current literature on the differential information between financial intermediaries and borrowers by theoretically investigating how changes in the market structure affect the lending behaviour of banks and their incentives to invest in information acquisition through screening and how this, in turn, affects their risk profile.

Importantly, there are no studies that theoretically establish a clear link between screening and credit risk, and this provides a solid ground for our research that scrutinises this relationship. Indeed, even though a few studies skim over this relationship (Freixas et al., 2007; Hakenes and Schnabel, 2010; Gomez and Ponce, 2014; Pennacchi, 2018), our study is, to the best of our 
knowledge, the first one that sheds the spotlight on the linkage between screening and risk offering clear and concrete results regarding its direction, potency, and validity.

An innovative feature in our model setup is that we deviate from the extant literature (e.g., Chiappori et al., 1995; Schnitzer, 1999; Boot and Thakor, 2000; Hyytinen, 2003; Pennacchi, 2018), which takes a pre-crisis perspective by assuming that market structure is endogenous in the sense that it is determined by the entry decisions as dictated by the profitability in the sector. We take a post-crisis perspective and treat the number of banks as exogenous on the basis of the following factors: first, the various government interventions in the form of bailouts, assisted failures, and non-market-based consolidations, which have been the main determinants of the banking market structure in the aftermath of the crisis; and second, the fact that the banking industry has been subjected to heavy regulation all the years following the crisis. In sum, the number of banks can be thought of as a policy makers' decision variable in our analysis.

Formal empirical evidence on the market structure-screening-risk nexus remains sparse in the literature. Hence, an additional innovation is that we provide real-world context to our theoretical model and to the relevant findings by conducting a cross-country analysis based on the G7 banking sectors. Our data period extends from 2000 to 2015 thus including the years prior, during, and after the crisis.

Several appealing results are derived when solving our model for the equilibrium price levels. When a bank reduces its lending rates, it succeeds in extending its share in the market. This is done by 'poaching' customers from its more expensive rivals. It is also demonstrated that an increase in competition lowers the equilibrium loan rates, rendering credit cheaper for all types of applicants. Therefore, more borrowers with either good or bad projects enter the loan market. As a consequence, stiffer competition has an increasing impact on credit risk. It is further found that when the market structure tends towards perfect competition, the travelling cost of borrowers becomes irrelevant in the setting of the optimal lending rate.

Notably, we offer new insights into the literature by lending support to the view that competition strengthens the incentives of banks to engage in screening. Moreover, we show that by investing in screening, a bank is able to charge good (bad) borrowers with a lower (higher) rate. That is, screening serves as a reliable device that financial intermediaries can resort to in order to protect their portfolios against bad credit and, hence, against the embedded risks which are more likely to occur under enhanced competition. 
Overall, we demonstrate that when market conditions are distorted, as has been the case with the recent crisis, this has a dilutive impact on the incentives mechanism of banks to screen their applicants. Indeed, the large-scale transformations that occurred in the banking market inevitably led financial institutions to reassess their incentives to invest in screening. The evidence of our empirical analysis is consistent with our theoretical framework and strongly supports the underpinnings of our model and the obtained findings.

The rest of the paper is as follows: Section 2 reviews the literature; Section 3 lays out our model of interbank competition with screening; Section 4 characterises the equilibrium and presents the key propositions; Section 5 discusses the results and the relevant implications; Section 6 furnishes our theoretical analysis with real-world context; Section 7 presents the conclusions.

\section{Related literature}

A substantial body of theoretical literature, dated prior to the outbreak of the recent financial crisis, is devoted to the relevance of market conditions in the screening function of banks; however, as highlighted below, little attention has been paid to this topic after the onset of the crisis. Moreover, there is no consensus in the extant literature (neither in the pre- nor in the postcrisis literature) on the relationship that holds between market structure and banks' incentives to screen their loan applicants.

Manove et al. (2001) construct a model whereby banks make a choice between screening the potential borrowers, or asking them to pledge collateral. The posting of collateral by borrowers is viewed as being a substitute to screening in that it induces banks to overlook screening even though this can transmit an accurate signal to banks regarding applicants' creditworthiness. In high levels of competition, the incentives of borrowers to post collateral increase and this makes banks reluctant to engage in screening. Cetorelli and Peretto (2000) demonstrate that, as the number of competitors in the banking market declines, the value added that banks attain from screening rises. Simply stated, competition negatively affects banks' incentives to generate information via screening, a view that is in line with that of Manove et al. (2001). In a similar vein, Cao and Shi (2001) show that increased competition amongst lenders to finance a borrower's project reduces the equilibrium level of screening. 
Hauswald and Marquez (2006) develop a spatial model of banking competition where the quality of banks' information-acquisition process decreases as the distance separating borrowers from banks gets higher. They find that tougher competition erodes bank rents and squeezes the resources that lenders devote to screening their applicants. As a consequence, banks become more vulnerable in taking faulty lending decisions. Lehner and Schnitzer (2008) also rely on a spatial competition model to examine how the entry of foreign banks affects the behaviour of their local counterparts in markets that are characterised by different degrees of liberalisation. They document that intensified competition due to the entry of foreign banks tends to lower the incentives of domestic banks to invest in screening technology.

Gomez and Ponce (2014) focus on the effect of competition on the efficiency of banks to screen potential borrowers, and on the consequences on borrowers' incentives to exert effort and to repay their loans. Their findings show that an increase in the number of banks leads to a lower level of loanable funds once a certain optimal threshold in the number of banks is reached at equilibrium. If competition increases, this reduces the effectiveness of banks' screening technology to the point that, other things being equal, the expected benefits become negative. Along the same lines, Broecker (1990), Shaffer (1998), and Freixas et al. (2007) focus on the impact of competition on the effectiveness of banks to screen loan applicants. Interestingly, all three studies show that more vigorous competition deteriorates the effectiveness of banks to screen the applicants.

Other studies, however, report a positive impact of competition on banks' incentives to screen would-be borrowers. Villas-Boas and Schmidt-Mohr (1999) employ a competition model à la Hotelling (1929) to show that competition strengthens the screening incentives of banks. As they point out, this can be explained by the fact that banks compete more aggressively for the most profitable applicants. In a similar vein, Hainz et al. (2013) explore how competition affects the use of collateral in bank credit markets and the results they obtain also move in the opposite direction of those of Manove et al. (2001). More concretely, they document that screening becomes more expensive as the distance between the bank and the applicant increases. This implies that increased competition makes the use of collateral less likely, by making the choice for screening more attractive. In other words, they find that the reduction of loan rates due to higher competition is associated with an increase in screening activity. 
Interestingly, other studies are not capable of documenting a robust link between market structure and the incentives of banks to obtain information about the creditworthiness of their applicants through screening. Dell' Arricia (2000), for example, shows that this relationship varies depending on which of the following two opposite effects prevails. On the one hand, fierce competition aggravates the adverse selection problem that banks face pushing them to invest more in screening. On the other hand, more competition is linked to higher incentives for banks to deviate from a screening equilibrium, as the additional market share for a deviating bank becomes larger. Therefore, it turns out that the sign of the examined relationship is determined by the relative strength of the above two contradictory effects. Likewise, Gehrig (1998) investigates the incentives of banks to produce information by allowing banks to choose the level of their screening effort. A rather ambiguous and inconclusive result is highlighted: the study concludes that the direction of the examined relationship depends on the value of identifying and attracting good projects relative to the value of detecting and avoiding bad projects, which differ amongst banking sectors.

It follows from the above discussion that there are no papers in the relevant literature that theoretically establish a link between screening and credit risk. More specifically, neither of the studies we review in this Section clearly demonstrates how banks use screening technology to distinguish between investment projects of high-risk from those of low-risk, and ultimately how screening is linked to credit risk. This holds also true for a bunch of additional theoretical studies, which involve screening as a key element in their analysis (Gehrig and Stenbacka, 2011; Bose et al., 2012; Karapetyan and Stacescu, 2014; Pennacchi, 2018).

\section{The model}

\subsection{The environment}

Our analysis relies on a model of spatial competition à la Salop (1979). We consider a banking market with two classes of players: a continuum of banks and a continuum of entrepreneurs. Both classes of players are risk-neutral and live for one period, which comprises two stages: Stage 1 and Stage 2. Entrepreneurs are located symmetrically around a circle of length 1, and their total mass is normalised to 1 . The role of geographical distance in the bank-borrower relationship reflected in our circle framework has been empirically highlighted by the works of Petersen and Rajan (2002) and Degryse and Ongena (2005) amongst others. Each entrepreneur is 
endowed with an indivisible project that requires an investment of a fixed amount of one unit of money. We assume that entrepreneurs have no initial wealth so that if a project is to be initiated, entrepreneurs must obtain credit from banks. As such, the term 'entrepreneurs' is used interchangeably with those of 'borrowers' and 'applicants' in what follows.

An investment project either succeeds with probability $p_{\theta} \in(0,1]$ yielding a stochastic return $R\left(p_{\theta}\right)>1$ or fails with probability $1-p_{\theta}$ and returns nothing. This is to say, $p_{\theta}$ denotes the repayment (success) probability of the investment project. The return, $R\left(p_{\theta}\right)$, is higher than 1 (unit of money) to safeguard that entrepreneurs have incentives to invest in the project. The parameter $\theta$ describes entrepreneurs' type and takes the following two values: $\{h, l\}$, where $h$ stands for entrepreneurs with high-quality projects, while $l$ represents entrepreneurs who have low-quality projects. Consequently, it holds that $p_{h}>p_{l}$ and $R\left(p_{h}\right)>R\left(p_{l}\right)>1$, which imply that good projects have a higher probability of success and produce higher returns if compared with bad projects. We therefore obtain that $p_{h} R\left(p_{h}\right)>p_{l} R\left(p_{l}\right)$, which shows that the expected returns of a good project are always higher than the expected returns of a bad project.

\subsection{Borrowers}

The fraction of good entrepreneurs is equal to $q(0<q<1)$, where $q$ is assumed to be common knowledge. That is, both parties know that in each point of the circle's periphery there is a mass $q$ of $h$-type entrepreneurs and a mass $(1-q)$ of $l$-type entrepreneurs. As regards the two-point distribution of $\theta$, we assume that this is public information. However, $\theta$ per se is observable only to entrepreneurs in the beginning of Stage 1. That is, entrepreneurs know about the quality of their projects, while this information is not known to banks. Nevertheless, banks have the expertise to determine entrepreneurs' capabilities and uncover the actual quality of their projects. As we mention later, this is made through screening in our model.

Each entrepreneur is required to express his/her preference for a particular type of loan by travelling along the circumference at a per length transportation cost $\tau_{\theta}>0$ to reach the bank that satisfies his/her type. We thus introduce heterogeneity in preferences in our model; this is to say, preferences are assumed to be sufficiently heterogeneous to allow the relocation of the entrepreneurs on the circle. The idea behind this is that entrepreneurs incur some disutility by conducting business with a bank that is not of their type. The distance $d_{\theta}>0$ that an entrepreneur 
covers to reach a particular bank is a measure of his/her disutility to buy a less-than-ideal product. ${ }^{1}$ The distance $d_{\theta}$ refers to the physical distance between banks and borrowers, which comprises a source of inefficiency for both players.

It has to be mentioned here that $\tau$ should not be interpreted in strictly geographical terms. Instead, it should be viewed as some type of transaction cost that each credit applicant needs to pay in order to borrow from the bank of his/her taste. Banks are required to pay more money to screen a more distant applicant, whereas the distance-related pecuniary cost (transportation cost) to approach a bank physically is higher for the distant applicants. Subsequently, the total cost of buying one unit of money equals to the sum of the bank lending rate (see Section 3.3 on this) increased by the total transportation cost $\left(\tau_{\theta} d_{\theta}\right)$ the entrepreneur has to sustain to reach the bank of his/her preference.

\subsection{Banks}

We now turn to introduce banks in our model. The whole market consists of $n \geq k$ banks (with $k$ being a positive integer), which, like entrepreneurs, are also symmetrically distributed on the unit circle. The assumption that $n \geq k$ safeguards that the number of banks can increase towards infinity but cannot fall below some threshold value $k$. Banks are profit maximisers and compete in prices (i.e., loan interest rates) to attract heterogeneous entrepreneurs who invest in risky projects. We do not model competition on the deposit market assuming that the supply of deposits is perfectly elastic at an interest rate that is normalised to zero.

Banks are faced with an informational problem in their lending decisions as they do not know the type of their applicants and thus the quality of the proposed projects. They therefore screen the entrepreneurs to obtain their type. Since screening is a costly activity, a bank is capable of identifying their type at a cost equal to $e \in(0,1]$ per unit invested. The screening cost $e$ can be viewed as the bank's screening effort: a larger $e$ corresponds to a more extensive effort. Following Manove et al. (2001), we assume that screening is non-contractible, so that banks cannot sell it to their customers as a service; also, that the signal that banks receive from screening is strictly proprietary in that it is not observable to any of their competitors. If information spillovers were to be assumed instead, a free-riding problem would arise, which

\footnotetext{
${ }^{1}$ For more on this point, the interested reader can refer to Schnitzer (1999).
} 
would curtail the incentives of banks to undertake screening. This, in turn, would possibly lead to an inefficient credit allocation. ${ }^{2}$

To continue, screening technology is perfect in the sense that the signal each bank receives is not noisy. We assume that banks have access to perfect screening technology only above some threshold value of $e>>0$ that may differ amongst banks, but that all banks have incentives to pay. To shed more light on this assumption, we can think of a bank that-conditional on the screening cost $e$ as well as on the other parameters of the model- decides not to pay $e$ to screen an applicant. The bank will learn the entrepreneur's type only after the loan has been granted and invested. ${ }^{3}$ In such a case, the loan may have been extended to a bad entrepreneur with a lowquality project. In the extreme case where all banks but one are engaged in screening, then that particular bank risks serving all the bad entrepreneurs in the market. This credible threat in the context of a game theory perspective provides all banks with solid incentives to screen their applicants at a cost $e$. Further, without the assumption that $e>>0$, banks would prefer to invest the lowest possible amount of money (i.e., $e \cong 0$ ) to screen entrepreneurs and obtain their type. Moreover, the level of $e$ is particularly relevant for the better understanding of our findings as will become clear later.

After distinguishing good from bad entrepreneurs through screening, banks proceed to discriminate among them in prices by offering a loan interest rate $r_{\theta}$ chosen from the set $\left\{r_{l,}, r_{h}\right\}$. The lending rate factor $r_{\theta}$ encompasses two main components: the repayment probability of the loan $p_{\theta}$ that reflects entrepreneurs' creditworthiness, and the administrative cost of lending which is assumed to be constant for all types of borrowers and independent of the distance $d_{\theta}$ that separates banks from entrepreneurs. Following Chiappori et al. (1995) and Hyytinen (2003), we assume that banks cannot observe the exact location of entrepreneurs on the circle, which means that price discrimination is not location-based. Put simply, banks do not engage in spatial pricing. By being offered distinct rates, entrepreneurs learn the type that has been assigned to them and travel to the bank that satisfies their type to apply for credit.

\footnotetext{
2 The seminal work of Cetorelli and Peretto (2000) provides a thorough analysis of the free-riding problem that emerges when the results of the screening process are observable to the rival banks.

${ }^{3}$ For more details on this point, see Dell' Arricia (2001).
} 


\subsection{Timing}

The time structure of the game is as follows. At stage 1, banks screen the entrepreneurs and reveal their type. Banks then compete to attract loan customers by simultaneously making their price offers to each of them based on the screening outcome. At stage 2, entrepreneurs observe the loan rates offered, and travel to the bank that proposed the most favourable contract to apply for credit. Clearly, in case two banks make the same offer, entrepreneurs choose the one which is nearer to his/her preferences. Moreover, entrepreneurs are indifferent between two banks in case they are required to pay the same total cost given by the sum of the loan rate paid to the bank plus the transportation cost.

\subsection{Relationship vs Transaction banking}

At this point, it is useful to make a distinction between relationship and transaction banking in the context of our analysis and clarify that our model is focused on the latter type of banking. ${ }^{4}$

Relationship banking refers to the provision of a variety of financial services towards the establishment of long-term relationships with customers through multiple interactions. Loans are packaged with other services so that the relationship with a borrower has a marketing value for the bank and, as such, the bank has to consider the overall cost of rejecting a loan when choosing the optimal screening effort. Relationship banking has been widely examined in the theoretical literature (see, e.g., Boot and Thakor, 2000; Manove et al., 2001; Dell' Ariccia and Marquez, 2004; Hauswald and Marquez, 2006) as well as in the empirical literature (see, e.g., Petersen and Rajan, 2002; Degryse and Ongena, 2005; Agarwal and Hauswald, 2010; Sääskilahti, 2016) either on a stand-alone basis or in comparison to transaction banking. The relevant studies focus on small business lending and either assume a multi-product banking market where both loans and deposits are offered, or distinguish between incumbent and de novo banks where the former institutions lend to the same business for the second time and, hence, have an informational advantage compared to the latter ones, or introduce collateral as a substitute for screening, or assume that bank decisions rely on 'soft' or proprietary information. Not all studies necessarily incorporate every one of the aforementioned characteristics when modelling relationship banking.

\footnotetext{
${ }^{4}$ Bolton et al. (2013) provide an excellent discussion of the differences and similarities between the two banking business models.
} 
On the other hand, as highlighted in Boot and Thakor (2000), transaction-based banking involves arm's length transactions with borrowers rather than long-term relationships. This business model treats each loan transaction as a single deal and focuses on the risk entailed in the loan contract. Also, in transaction-based practices, the price of the service rather than the relationship that the firm holds with the financial intermediary is the means of attracting a steady stream of business. Studies that shed the spotlight on this form of banking share the following characteristics. They: a) focus on a single service, paying little or no attention to the synergies between various services, b) assume homogeneous banks in the sense that banks have no prior information on the risk profile of loan applicants, and c) examine the acquisition of 'hard' instead of 'soft' information. The model we develop as presented above combines all three features and, hence, our study falls into the area of transaction-based banking.

\section{Equilibrium}

The equilibrium solution is obtained by backward induction, i.e., we first solve Stage 2 and then Stage 1. As earlier mentioned, in Stage 2, the entrepreneur views the interest rate offered by each bank and travels to the bank of his/her interest. For any given rate $r_{\theta}$, the expected net return of a type- $\theta$ entrepreneur is given by:

$$
p_{\theta}\left[R\left(p_{\theta}\right)-r_{\vartheta}\right]-\tau_{\theta} d_{\theta}
$$

Note that the lending interest rate $r_{\theta}$ is multiplied by $p_{\theta}$ because there is a possibility $\left(1-p_{\theta}\right)$ that the loan will not be repaid.

We can now formulate entrepreneur $\theta$ 's participation constraint, which ensures that it is in the interest of every entrepreneur to participate in the loan market. An entrepreneur applies for credit only if his/her expected net profit is non-negative:

$$
p_{\theta}\left[R\left(p_{\theta}\right)-r_{\theta}\right]-\tau_{\theta} d_{\theta} \geq 0 \Leftrightarrow d_{\theta} \leq \frac{p_{\theta}\left[R\left(p_{\theta}\right)-r_{\theta}\right]}{\tau_{\theta}}
$$


Since $d_{\theta}>0$ by definition, it must hold that $\frac{p_{\theta}\left[R\left(p_{\theta}\right)-r_{\theta}\right]}{\tau_{\theta}}>0$. It is assumed that $p_{\theta}$ and $\tau_{\theta}$ are larger than zero, which implies that $R\left(p_{\theta}\right)-r_{\theta}$ must also be larger than zero, i.e., $R\left(p_{\theta}\right)>r_{\theta}$. The latter condition stands for the project's viability constraint and shows that the return of an investment project must always outweigh the lending cost. In fact, this condition ensures that eq. (2) is not violated.

Assuming that eq. (2) holds with equality and solving for the distance variable $d_{\theta}$, we obtain:

$$
d_{\theta}=\frac{p_{\theta}\left[R\left(p_{\theta}\right)-r_{\theta}\right]}{\tau_{\theta}}
$$

Eq. (3) shows that it is not profitable for any entrepreneur to apply for a loan beyond $d_{\theta}$. Since entrepreneurs have been informed the type that has been assigned to them in the beginning of Stage 2 when banks have made them a price offer (either $r_{h}$ or $r_{l}$ ), we move to extract the following two equations which are produced by eq. (3) for each of the two types of entrepreneurs:

$$
\begin{aligned}
& d_{h}=\frac{p_{h}\left[R\left(p_{h}\right)-r_{h}\right]}{\tau_{\theta}} \\
& d_{l}=\frac{p_{l}\left[R\left(p_{l}\right)-r_{l}\right]}{\tau_{\theta}}
\end{aligned}
$$

We can now turn to characterise the Nash equilibrium in the loan market. Our focus is restricted on symmetric equilibrium in location and interest rates. That is, we do not examine collusive equilibria as those sustainable with trigger strategies. As mentioned earlier, each of the $n$ banks makes a price offer to potential borrowers. Without loss of generality, we can assume that a typical bank $j$ offers $r_{\theta}^{j}, j=1,2, \ldots, n$ and that the transportation $\operatorname{cost} \tau_{\theta}$ is small enough (but not equal to 0) for the banking market to be wholly covered. In this scheme of things, bank $j$ is located equidistantly between banks $j+1$ and $j-1$ that charge $r_{\theta}^{j+1}$ and $r_{\theta}^{j-1}$, respectively. An 
entrepreneur of type $\theta$ located at a distance $d_{\theta} \in(0,1 / n]$ from bank $j$ is indifferent between borrowing from $j$ and borrowing from its nearest neighbour, say $j+1$, if the equation below holds true:

$$
p_{\theta}\left[R\left(p_{\theta}\right)-r_{\theta}^{j}\right]-\tau_{\theta} d_{\theta}=p_{\theta}\left[R\left(p_{\vartheta}\right)-r_{\theta}^{j+1}\right]-\tau_{\theta}\left(\frac{1}{n}-d_{\theta}\right)
$$

Eq. (4) is the indifference condition, which reveals the exact location of the type- $\theta$ marginal borrower who is located half-way between bank $j$ and bank $j+1$. Solving eq. (4) for $d_{\theta}$ yields:

$$
d_{\theta}\left(r_{\theta}^{j}, r_{\theta}^{j+1}\right)=\frac{1}{2 n}+\frac{p_{\theta}\left(r_{\theta}^{j+1}-r_{\theta}^{j}\right)}{2 \tau_{\theta}}
$$

Hence, bank $j$ faces the following demand for loans:

$$
L_{\theta}^{j}\left(r_{\theta}^{j}, r_{\theta}^{j+1}\right)=2 d_{\theta}=\frac{1}{n}+\frac{p_{\theta}\left(r_{\theta}^{j+1}-r_{\theta}^{j}\right)}{\tau_{\theta}}
$$

From the expression $2 d_{\theta}$ in eq. (6), we can infer that two marginal borrowers exist in the market: one on the left-hand side, and one on the right-hand side. We also notice that for $r_{\theta}^{j}=r_{\theta}^{j+1}$, we obtain $d_{\theta}=\frac{1}{2 n}$ which corresponds to the mid-point between the two adjacent banks $j$ and $j+1$. Moreover, we can obtain that $L_{\theta}^{j}=\frac{1}{n}$, implying that the $n$ banks equally share the borrower population. Like in the Salop's (1979) model, the ratio $\frac{1}{n}$ stands for a measure of bank's market power.

By looking at eq. (6) more closely, we observe that the loan demand function of bank $j$ is declining in its own rate $r_{\theta}^{j}$ and increasing in its rival bank's rate $r_{\theta}^{j+1}$. This means that bank $j$ can attract a larger number of would-be borrowers if it lowers its lending rate. The converse also holds true: an increase in the lending rate factor is enough to compel borrowers to move away 
from the relatively more expensive bank. Importantly, neither the number of banks $n$, nor the level of transportation $\operatorname{cost} \tau_{\theta}$ vitiates the power of this finding. In other words, borrowers travel to the bank that offers the lowest rate regardless of the degree of competition in the market and the relevant transportation cost.

Banks price entrepreneurs on the basis of their type. Consequently, for $\theta=h$, the loan demand function (eq. 6) takes the following form:

$$
L_{h}^{j}\left(r_{h}^{j}, r_{h}^{j+1}\right)=2 d_{h}=\frac{1}{n}+\frac{p_{h}\left(r_{h}^{j+1}-r_{h}^{j}\right)}{\tau_{\theta}}
$$

Correspondingly, for $\theta=l$ we obtain:

$$
L_{l}^{j}\left(r_{l}^{j}, r_{l}^{j+1}\right)=2 d_{l}=\frac{1}{n}+\frac{p_{l}\left(r_{l}^{j+1}-r_{l}^{j}\right)}{\tau_{\theta}}
$$

We can now turn to consider Stage 1. The optimisation problem of bank $j$ is regarded as choosing the optimal lending rates $r_{h}^{* j}$ and $r_{l}^{* j}$ by appropriately pricing heterogeneous borrowers through the screening mechanism, given similar choices of the other banks. Hence, bank $j$ 's expected net returns per unit of loans granted to $h$-type and $l$-type borrowers are as follows:

$$
u_{h}^{j}\left(r_{h}^{j}\right)=q p_{h} r_{h}^{j}-(1+e)
$$

and

$$
u_{l}^{j}\left(r_{l}^{j}\right)=(1-q) p_{l} r_{l}^{j}-(1+e)
$$

Accordingly, bank $j$ solves the following maximisation problem:

$$
\max _{r_{h}^{j}, r_{l}^{j}} \pi^{j}=u_{h}^{j}\left(r_{h}^{h}\right) L_{h}^{j}\left(r_{h}^{j}, r_{h}^{j+1}\right)+u_{l}^{j}\left(r_{l}^{j}\right) L_{l}^{j}\left(r_{l}^{j}, r_{l}^{j+1}\right)
$$

If we substitute eqs. (6a), (6b), (7a), and (7b) into eq. (8), we get: 


$$
\begin{aligned}
\max _{r_{h}^{j}, r_{l}^{j}} \pi^{j}= & {\left[q p_{h} r_{h}^{j}-(1+e)\right]\left[\frac{1}{n}+\frac{p_{h}\left(r_{h}^{j+1}-r_{h}^{j}\right)}{\tau_{\theta}}\right] } \\
& +\left[(1-q) p_{l} r_{l}^{j}-(1+e)\right]\left[\frac{1}{n}+\frac{p_{l}\left(r_{l}^{j+1}-r_{l}^{j}\right)}{\tau_{\theta}}\right]
\end{aligned}
$$

We can now differentiate the profit function with respect to $r_{h}^{j}$ and $r_{l}^{j}$. The symmetric price equilibrium is obtained by setting $r_{h}^{j}=r_{h}^{j+1}$ and $r_{l}^{j}=r_{l}^{j+1}:^{5}$

$$
\begin{aligned}
& r_{h}^{* j}=\frac{1}{p_{h}}\left[\frac{\tau_{h}}{n}+\frac{(1+e)}{q}\right], \text { when } \theta=h \\
& r_{l}^{* j}=\frac{1}{p_{l}}\left[\frac{\tau_{l}}{n}+\frac{(1+e)}{(1-q)}\right], \text { when } \theta=l
\end{aligned}
$$

Proposition 1. An increase in competition reduces the equilibrium loan rate no matter the type of the borrower

Proof. The first order conditions of eqs. (10a) and (10b) with respect to $n$ are $\frac{\partial r^{* j}}{\partial n}=-\frac{\tau_{h}}{p_{h} n^{2}}<0$ and $\frac{\partial r^{* j}}{\partial n}=-\frac{\tau_{l}}{p_{l} n^{2}}<0$, respectively. Hence, both $r_{h}^{* j}$ and $r_{l}^{*_{j}^{j}}$ decrease with the number of banks $n$, which shows that the level of competition is negatively linked with the equilibrium lending rates regardless of the type of applicants. This is to say, the impact of competition on the equilibrium rates is uniform across the two types of borrowers, implying that both good and bad entrepreneurs face lower rates under enhanced competition. Therefore, as competition increases a larger number of entrepreneurs of any type are expected to enter the market attracted by the lower funding cost. That is, not only good but also bad projects with lower probability of success which entail higher credit risk are to be proposed to the banks for potential funding. This proposition is in line with the mainstream view in the literature that provides support to the

\footnotetext{
5 The proof is relegated to Appendix A.
} 
negative relationship that holds between the degree of competition and the cost of lending. For instance, Boyd and De Nicolò (2005) and De Nicolò and Loukoianova (2007) find that banks charge lower loan rates when competition is increased and this is a counter-incentive in the borrowers' risk-taking decision.

Proposition 2. In high levels of competition, transportation cost is irrelevant in the setting of the optimal loan rate

Proof. By looking at the first order conditions of eqs. (10a) and (10b) with respect to the number of banks $n$, we can infer that when $n>>0$, it holds that $\tau_{\theta} / n \approx 0$ where $\theta \in\{h, l\}$. This means that, in a very competitive loan market where $n$ is sufficiently large, the particular type and level of transportation $\operatorname{cost} \tau_{\theta}$ plays no role in the optimal rate setting. Any additional bank entry that would drive the market further nearer to perfect competition (i.e., $n \rightarrow \infty$ ) would strengthen the power of this proposition since $\tau_{\theta} / n \rightarrow 0$.

Proposition 3. Screening serves as a reliable protective mechanism for banks against credit risk Proof Suppose there is the maximum possible heterogeneity between borrowers in the economy, i.e., $\quad q=\frac{1}{2}$. Substituting $q=\frac{1}{2} \quad$ to eqs. (10a) and (10b) produces $r_{h}^{{ }^{* j}}<r_{l}^{* j}$ since $\frac{1}{p_{h}}\left[\frac{\tau_{h}}{n}+2(1+e)\right]<\frac{1}{p_{l}}\left[\frac{\tau_{l}}{n}+2(1+e)\right] \Rightarrow p_{h}>p_{l}$, which holds by assumption. The inequality $r_{h}^{* j}<r_{l}^{* j}$ implies that the bank offers a low loan rate that is equal to $r_{h}^{* j}$ to entrepreneurs with high-quality projects and a high rate that equals to $r_{l}^{* j}$ to those with low-quality projects. This occurs because banks pay a cost $e$ to screen the would-be borrowers and reveal their type and learn the probability of success $p_{\theta}$ of their investment projects. Since $p_{\theta}$, which is a component of $r_{\theta}$ (together with the administrative cost of lending which, however, remains unchanged between the two types of borrowers as mentioned above) is lower for bad projects and higher for good projects, i.e., $p_{l}<p_{h}$, a bank charges good (bad) applicants with a lower (higher) rate. In so doing, the bank manages not to expose its loan portfolio to the credit risk assumed in low-quality projects. 
To provide further theoretical justification to Proposition 3, we highlight below that screening acts as an effective device against credit risk, even in the case that the screening technology that banks use to detect good and bad projects is imperfect. ${ }^{6}$ Towards this, we assume that screening (which continues to incur a cost $e$ ) produces an imperfect signal $s \in\{h, l\}$ and that a bank accepts a loan application when it observes a signal $h$ and rejects an application when the signal that it obtains is given by $l$. We define $\alpha(e)=\operatorname{Pr}(h \mid H, e)$ as the probability for correctly accepting a high-quality project or, alternatively, the probability of correctly observing a signal $h$, where $H$ stands for the entire population of entrepreneurs with high-quality projects $h$. We also define $\beta(e)=\operatorname{Pr}(h \mid L, e)$ as the probability for falsely accepting a high-quality project or, alternatively, the probability of erroneously observing a signal $h$, where $L$ stands for the entire population of entrepreneurs with low-quality projects $l$. Consequently, imperfect screening technology produces a type-I error with probability $1-\alpha(e)$ and a type-II error with probability $\beta(e)$. The higher is the screening cost $e$, the higher is the ability of the bank to obtain a true signal and distinguish the entrepreneurs with high-quality projects with $\alpha^{\prime}(e)>0, \alpha^{\prime \prime}(e) \leq 0$, from those with low-quality projects with $\beta^{\prime}(e)<0, \beta^{\prime \prime}(e) \geq 0$. In the special case of 'no screening' (i.e., $\left.e=0\right)$, banks are not in the position to obtain any information beyond the known distribution of population of high- and low-quality projects, so that $\alpha(0)=q$ and $\beta(0)=1-q$. On the other extreme, when $e=1$ a perfect (or completely informative) screening technology is assumed so that $\alpha(1)=1$ and $\beta(1)=0$.

Proposition 4. Increased competition induces banks to invest more in screening Proof. Eq. (10a) can be written as follows:

$$
r_{h}^{* j}=\frac{\tau_{h}}{n p_{h}}+\frac{(1+e)}{q p_{h}} \Leftrightarrow r_{h}^{* j}=\frac{\tau_{h} q+n+n e}{n q p_{h}} \Leftrightarrow n(1+e)=n q p_{h} r_{h}^{* j}-\tau_{h} q \Leftrightarrow e=q p_{h} r_{h}^{* j}-\frac{\tau_{h} q}{n}-1
$$

If we compute the first derivative of the above equation with respect to $n$, we get: $\frac{\partial e}{\partial n}=\frac{\tau_{h} q}{n^{2}}$, which is positive since $\tau_{h} q>0$, and $\tau_{h}, q>0$, by assumption. ${ }^{7}$ This shows that the greater the

\footnotetext{
${ }^{6}$ Studies that use imperfect screening technologies are those of Hainz et al. (2013) and Lehner and Schnitzer (2008).

${ }^{7}$ It is straightforward that we obtain the same results if, following the same process, we differentiate (10b) -instead of (10a)- with respect to $n$.
} 
number of competitors $n$ in the market, the larger the screening cost $e$ that each competitor incurs. In simple terms, this proposition implies that banks invest more in screening technology when competition increases. Put differently, under mounting competition, banks are willing to pay a higher cost to obtain the actual type of their applicants. That is, the threshold value of $e$ for each bank which ensures the perfect screening outcome increases as competition becomes tougher. The present proposition is in agreement with the results of the studies of Hainz et al. (2013) and Villas-Boas and Schmidt-Mohr (1999), but stands in sharp contrast to those of Manove et al. (2001), Hauswald and Marquez (2006) and Lehner and Schnitzer (2008) who find that intense competition reduces the rents of banks and decreases their overall incentives to screen their credit applicants. The proposition is also in conflict with the view of Cetorelli and Peretto (2000), who, though relying upon the assumption that screening information is transferable and not proprietary (as it is the case in our analysis), demonstrate that competition negatively affects banks' incentives to generate information.

\section{Discussion}

In what follows, we discuss our key findings and present several insights together with a set of policy and business implications. To begin with, we show that borrowers are willing to travel to the bank that offers the lowest rate regardless of the degree of competition in the market and the relevant transportation cost. Therefore, each bank has incentives to poach borrowers from the competing banks by reducing its lending rate in an attempt to expand its market share. ${ }^{8}$ In other words, it is in the interest of each bank to offer a cheaper loan contract to encroach on its close rivals' market, as this, in turn, leads to the enhancement of the bank's share in the market and to a potential increase in its rents. This is the so-called 'business-stealing' effect, which has been widely documented in the theoretical and empirical corporate finance literature (see, e.g., Mankiw and Whinston, 1986; Raith, 2003; Davis, 2006; Baggs and de Bettignies, 2007). In the context of our research, this effect implies that when a bank lowers its price as a result of the increased competition as we discuss below, the rival banks turn out to be relatively more expensive. Due to this price advantage, the bank finds it easier to attract business from its competitors. Conversely, when a bank raises its lending rate above the equilibrium rate, this

\footnotetext{
${ }^{8}$ The rationale behind the concept of 'poaching' can be traced in the study of Bouckaert and Degryse (2006) as well as in that of Hauswald and Marquez (2006).
} 
discourages the bank's borrowers, who now seek to travel to a relatively cheaper institution. Notably, transportation cost is found to play no role in the decision of entrepreneurs to travel to (move away from) a bank that decreases (increases) its lending rates.

We report a negative relationship between the number of banks in the market and the level of equilibrium lending rates, which suggests that competition has a considerably decreasing impact on the cost at which credit is available. This means that a larger number of banks give rise to intensive price competition in the banking market, which results in a lower lending cost. Interestingly, the interest rate that borrowers pay on their loans drops as the market structure of the banking sector becomes more competitive regardless of the type of each borrower. That is, good but also bad borrowers with projects of lower probability of success which entail higher risk are expected to take advantage of this decreased cost. Therefore, it can be inferred that enhanced competition has an increasing impact on the level of credit risk in the banking market. In line with our argument, Freixas et al. (2007) show that a larger number of banks raises the probability that bad entrepreneurs will eventually obtain a loan. The intuition is simple: when the number of banks in the market increases, bad entrepreneurs are more likely to apply for a loan. They therefore have a higher probability of finding a bank that will accept their application.

We further find that the importance of transportation cost in the setting of equilibrium loan rates declines as the number of banks increases. The condensed significance of transportation cost as a result of increased competition, coupled with the previously mentioned findings, indicates that fiercer competition reduces interest rates as it shrinks the average distances between all possible combinations of borrowers and neighbouring banks. In other words, as the cost of lending declines, more entrepreneurs are expected to enter the loan market, which implies that intensified competition leads to a greater degree of openness in the market.

To continue, we document that by investing in screening, a bank can charge good (bad) entrepreneurs with a lower (higher) rate. Hence, screening works as a key tool for banks to distinguish good from bad investment projects: it assists banks to price discriminate each project as appropriate by revealing the type of the loan applicants to the bank that conducts screening tests. Therefore, screening acts as a mitigation mechanism for the informational asymmetries related to the unobservable applicants' creditworthiness, which are inherent in the lenderborrower relationship. As a result, screening enhances the quality of a bank's loan portfolio as it provides the bank with the knowledge needed to reject a risky project and to accept a less risky 
one. Consequently, screening constitutes an effective device against loan losses because it reduces the probability of both Type-I and Type-II errors, which reflect the two sources of credit risk.

Importantly, we report an upsurge in banks' screening cost as a result of the increased competition in the lending market, which is in line with the theoretical predictions of Villas-Boas and Schmidt-Mohr (1999) and Hainz et al. (2013). The main interpretations to be placed upon this finding are as follows. First, the level of credit risk that banks are subjected to in a more competitive environment tends to be higher. This is because banks are more prone to make mistakes in their lending decisions as the number of credit applicants and, hence, that of bad applicants increases due to the intensified competition as documented above. To protect their portfolios from the increased threat of credit risk, banks turn to invest a larger amount of money in screening technology, or, alternatively, to devote more effort into screening, which incurs a higher cost. Second, as highlighted earlier, increased competition exerts a downward pressure on lending rates. Lowering the loan prices raises the screening cost, because greater credit rationing is required if banks are to screen out the risky borrowers. And, third, in line with Bose et al. (2012), if a bank anticipates a reduction in the expected returns from a proposed project due to higher credit risk, this can produce a pronounced increase in the screening of prospective borrowers, with substantial corresponding welfare effects.

An alternative interpretation of the reported increase in screening cost due to the enhanced competition is grounded on the view of Acharya et al. (2006) according to which the informational effectiveness of financial institutions is lower in highly competitive markets. Similarly, Shaffer (1998) argues that the screening process is less effective in less concentrated markets, and Gomez and Ponce (2014) show that more vigorous competition deteriorates the effectiveness of banks to screen applicants. On the whole, screening is a reliable device which can help banks to collect borrower-specific information that constitutes a shield against bad loans. Banks are required to incur a higher screening cost under fiercer competition in order to maintain the quality of information production and acquisition.

In sum, our results demonstrate that market structure is robustly linked to bank lending behaviour and to the incentives of banks to invest in information acquisition via screening. Historically, financial crises and the structure of the banking market have been strongly interrelated with each other. In a crisis, the number of distressed institutions increases, and this, 
in turn, leads to an upsurge in the volume of bankruptcies, liquidations, and consolidations. Consequently, the number of banks and, hence, the level of competition is drastically reduced (Pérez Montes, 2014; Sääskilahti, 2016).

Based on our overall findings, we can argue that the large-scale transformations that occurred in the banking industry as a result of the crisis inevitably led financial institutions to reassess their incentives to invest in screening. Specifically, the relaxation of the competitive market structure due to the massive consolidations, bailouts, and failures reduced the incentives of banks to screen their loan applicants. Put differently, the decrease in competition induced banks to slow down their screening effort. Bose et al. (2012) show that a bank often experiences increasing marginal returns to screening in a standard setting where the bank can decide how intensively to screen the investment projects of prospective borrowers. These returns imply that even small changes in industry parameters, such as, e.g., the degree of competition, can lead to large changes in the equilibrium screening intensity.

A different interpretation is that the crisis has allowed the banking market to evolve into a system where banks are more effective in screening the potential borrowers and this is the reason why a reduction in the relevant cost is reported. This means that the effectiveness of the screening technology has been improved as a result of the decrease in the number of banks in the market. The conceptual basis of this argument can be found in the Schumpeterian concept of 'creative destruction', which, in the context of our research, refers to the emergence of a new banking market architecture through the devastating effects of the crisis on the sector that allows banks to operate more effectively. ${ }^{9}$ To give an example, the majority of banks that failed during the crisis were small-to-medium sized banks; on the other hand, those that were bailed out by the regulatory authorities were large and systemically important institutions. In addition, the numerous mergers and acquisitions that took place gave birth to a bunch of new large banks. Since smaller banks have admittedly a more limited access to the information set of loan applicants compared to larger banks, the post-crisis banking sector which consists of a higher number of large banks and a lower number of small banks is more effective in screening. ${ }^{10}$

\footnotetext{
${ }^{9}$ We thank an anonymous reviewer for providing us with the relevant insight.

${ }^{10}$ Marquez (2002) shows that small banks possess less information about the market than large banks and, hence, the former banks are less effective in screening.
} 
Taken together, when market conditions are significantly distorted as has been the case in the global financial crisis, this has a dilutive impact on the incentives mechanism of banks to screen their applicants.

\section{Empirical evidence}

We provide real-world context to our theoretical model by conducting a cross-country analysis based on the G7 economies. Our focus on these economies is due to several important reasons. First, the G7 banking sectors were seriously hit by the crisis and have therefore undergone considerable changes in their market structure due to the large-scale bailouts, mergers, acquisitions and failures. Second, an understanding of the competition-risk dynamics in the leading world economies is vital because these set the tone for other economies to follow in so far as the best practices in bank regulation and supervision are concerned. And, third, G7 is the most representative group of economies in terms of banking and financial services sophistication, business models, and standards to which all other western-type economies tend to adhere.

We focus on commercial banks by filtering out the cooperative, savings, and investment banks as well as the credit unions and credit associations. Even though some of these institutions take deposits and grant loans similar to commercial banks, they often have other business objectives to satisfy. In addition, they do not attract the same regulatory scrutiny and oversight as commercial banks, which makes their analysis a rather arduous and misdirected exercise. Our data period extends from 2000 to 2015 and thus include the years preceding the financial crisis, the crisis period itself, as well as the years that followed the crisis.

\section{Table 1}

Data refinement. This table reports the filters we apply to obtain the final sample of banks. Bank-year observations refer to commercial banks from the G7 economies over the period 2000-2015. Data are collected from the Bureau Van Dijk Bankscope database.

\begin{tabular}{lc}
\hline Applied filters & $\begin{array}{c}\text { Bank-year } \\
\text { observations }\end{array}$ \\
\hline Initial sample & 53,616 \\
Missing observations for more than half of the sample years & 3,129 \\
Missing income statement observations & 63 \\
Observations with negative equity capital values & 15 \\
Observations with equity capital values in the top 1\% of the distribution & 397
\end{tabular}


We obtain our sample banks from the Bureau Van Dijk Bankscope database. As shown in Table 1, our initial sample consists of 53,616 bank-year observations having accounted for mergers and acquisitions that took place during the examined period. We ensure that banks appear separately in the sample before M\&As and only the merged entity or the acquiring bank is included in the sample after the relevant event.

We apply several filtering rules to eliminate the non-representative data. We exclude the observations which are linked to banks with: a) missing data for more than half of our sample years (that is, 8 years or more); b) missing income statement data; c) negative equity capital values; and d) equity capital levels in the top $1 \%$ and bottom $1 \%$ of the distribution as a means of combating the likely dominance of our study by the U.S. banks, which comprise the majority of our sample banks as shown in Table 2 that follows. Our refined sample consists of 49,625 bankyear observations and is composed of 2,899 commercial banks. The detailed breakdown of the sample banks in each of the G7 economies is presented in Table 2.

\section{Table 2}

Breakdown of sample banks. This table presents the bank-year observations and the number of banks per G7 country in our sample.

\begin{tabular}{lcc}
\hline Country & Bank-year observations & Number of banks \\
\hline Canada & 328 & 57 \\
France & 2,137 & 168 \\
Germany & 280 & 54 \\
Italy & 477 & 99 \\
Japan & 168 & 30 \\
United Kingdom & 3,331 & 304 \\
U.S. & 42,904 & 2,187 \\
\hline Total & $\mathbf{4 9 , 6 2 5}$ & $\mathbf{2 , 8 9 9}$ \\
\hline
\end{tabular}

We resort to the empirical literature to estimate the market structure of the banking sectors of the G7 economies. Following Claessens and Laeven (2004), Schaeck et al. (2009), and Schaeck and Cihak (2012) amongst others, we use the Panzar and Rosse (1987) H-Statistic as a measure of market conditions. ${ }^{11}$ The value of $\mathrm{H}$-Statistic is negative for a monopolistic banking market, equals to 1 for a purely competitive market and ranges between 0 and 1 for monopolistic

\footnotetext{
${ }^{11}$ The calculation of $H$-Statistic is described in Appendix B.
} 
competition. We also employ the Herfindahl-Hirschman Index $(H H I)$ in our analysis in line with Berger et al. (2009), Beck et al., (2013), and Akins et al. (2016). This is calculated as the sum of squares of the market share of each sample bank using total loans as the input variable. Higher values of $H H I$ indicate greater market concentration. Like the five- or the three-bank concentration ratios, $H H I$ captures a structural market characteristic (i.e., concentration) and is, therefore, theoretically underpinned by the Structure-Conduct-Performance (SCP) hypothesis which can be traced back to the seminal work of Bain (1951). According to this hypothesis as documented in the banking literature (see, e.g., Berger and Hannan, 1989; Neumark and Sharpe, 1992; Khan et al, 2018), the degree of concentration exerts a negative impact on competition. More concretely, the level of concentration demonstrates the extent to which the largest institutions contribute to the output of the banking industry. A higher level of concentration implies more market power and, hence, less competition. However, it should be noted that more concentrated banking markets are not necessarily less competitive. ${ }^{12}$

As regards the risk that is entailed in the loan contracts, this is measured by the ratio of nonperforming loans to total loans (NPL) in accordance to the relevant literature (Berger et al., 2009; Jimenez et al., 2013; Kick and Prieto, 2015). The nonperforming loans ratio is an ex post measure of credit risk. It reflects the loan portfolio risk embedded in bank balance sheets, only after its materialisation. Like loan loss provisioning, non-performing loans are procyclical, as they are basically linked to contemporaneous problem loans, so that the relevant ratio rises during an economic downturn when credit risk materialises (Laeven and Majnoni, 2003; Pool et al., 2015).

In line with our theoretical framework, we also account for the volume of bank loans granted to entrepreneurs by using the ratio of business loans to bank total assets $(L A)$. The loan-to-asset ratio is a standard measure of the bank lending activity in the literature (Chronopoulos et al., 2015; Caglayan and Xu, 2016).

Table 3 displays the mean values for all four variables we employ in our empirical analysis ( $H H I, H$-statistic, $L A, N P L$ ). The means are calculated per year and per country using the entire sample period (2000-2015). As discussed below, the empirical evidence is consistent with our theoretical framework and provides strong support to the conceptual underpinnings of our

\footnotetext{
${ }^{12}$ We thank the Associate Editor of the European Journal of Finance for pointing this out.
} 
theoretical model and to the findings we derive by solving for the equilibrium prices (eqs. 10a and 10b). 
Table 3

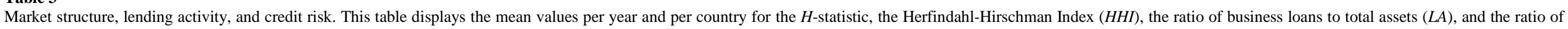
non-performing loans to total loans (NPL).

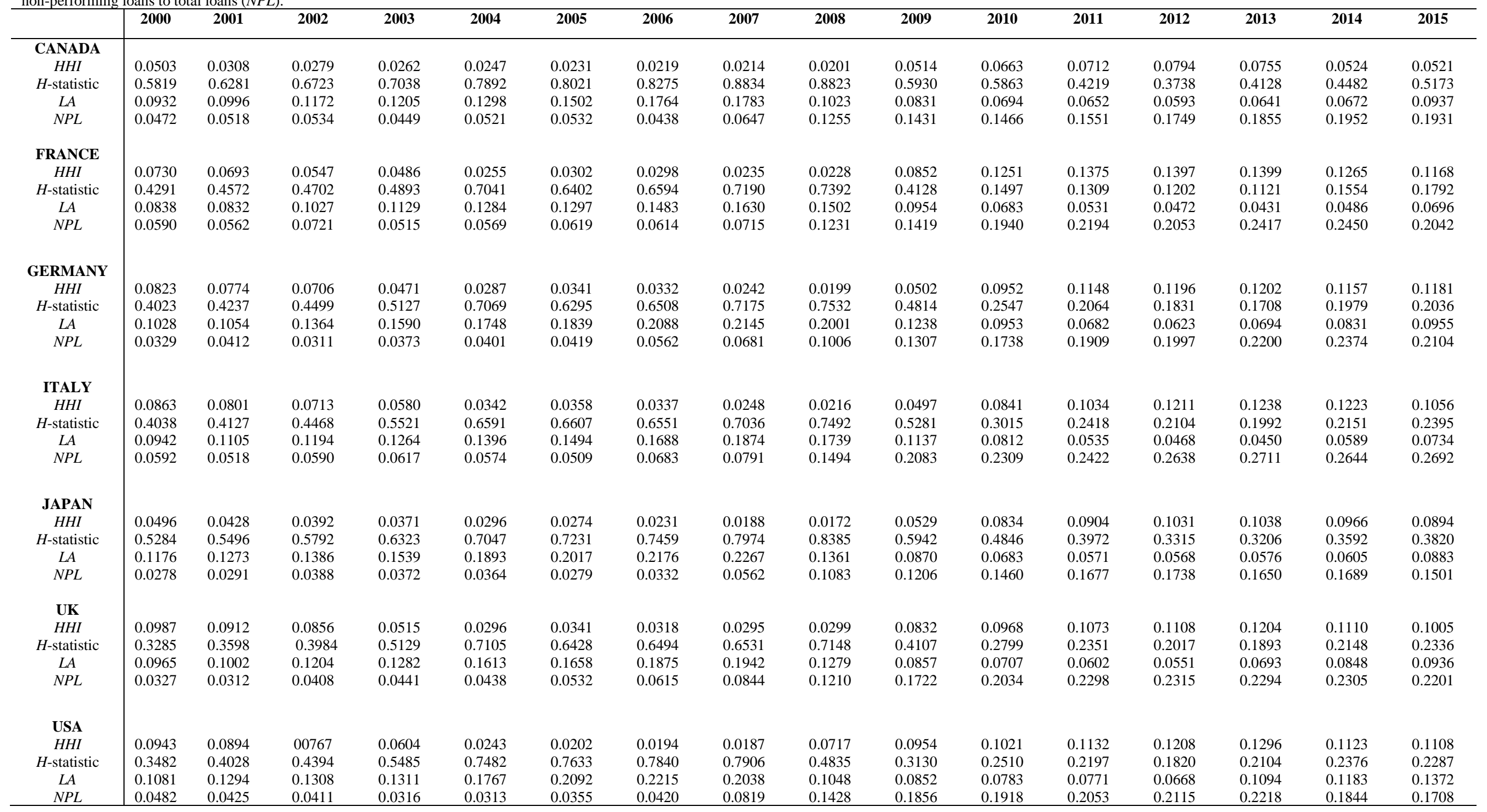


The values of $H$-statistic are all positive and below unity, revealing that the G7 banking markets operate under monopolistic competition. This provides strong support to our choice of the Salop (1979) model, as it offers one of the most representative environments in the literature for modelling a monopolistically competitive market. Importantly, $H$-statistic literally follows the same pattern across the G7 banking sectors. It gradually increases during the pre-crisis period (2000-2008), implying a progressively stiffer competition with respect to time; it reaches a peak in 2008 (in 2007 for the U.S.), then sharply decreases in 2009 (in 2008 for the U.S.), and continues to decrease until 2013. It starts to grow towards the end of our data period, i.e., in 2014 and 2015, revealing an increase in competition in the post-crisis era. Overall, the reported pattern vividly reflects the shock to the market conditions after the outbreak of the crisis due to the massive government bailouts, the numerous failures, and the large-scale consolidations, which we have extensively discussed so far and which have largely motivated our research.

The mean values of $H H I$ corroborate the results obtained for the $H$-statistic. Starting with the pre-crisis years, $H H I$ is found to be steadily reduced, meaning that concentration shrinks and that market is moving towards a more competitive structure during this period as dictated by the SCP paradigm. In 2009 (in 2008 for the U.S.), we report a sudden distortion in market conditions as a result of the enormous changes in the banking business environment. This distortion leads to a much more concentrated market structure in all the G7 banking industries as the crisis deepens and widens. This is demonstrated by the gradual increase in HHI over the period 2009-2013. From 2014 onwards when the crisis essentially came to a halt, we report a clear, but slow return towards a less concentrated market structure.

Our empirical results are supported by Soedarmono et al. (2013), who point out that financial crises lead to a shrinkage in the population of small banks and to the emergence of new large banks or to the expansion of the existing ones. Along these lines, De Guevara et al. (2005) find that consolidations in the event of a crisis increase the market power of banks. Moreover, Berger and Roman (2015) show that the financially supported banks in the recent crisis exhibit higher market shares compared with unsupported banks, or those that are left by authorities to go bankrupt. Consistent with this view, Koetter and Felix (2016) indicate that the U.S. Congressional Oversight Panel raises concerns that the supported banks are provided with a competitive advantage that leads to market consolidations, which, may, in turn, be detrimental 
for smaller banks. Similarly, Hakenes and Schnabel (2010) show that blanket guarantees equip banks with competitive advantages in funding markets.

The lending activity of banks $(L A)$ is found to increase consistently throughout the pre-crisis years in all sample economies. This is in line with our theoretical findings, which suggest that the fiercer competition in the years preceding the crisis lowered the lending cost, and, hence, led to an enhanced activity in the loan market. In 2009, $L A$ harshly falls and continues to decrease in the following years reflecting a considerable contraction in the business credit market, which comes to an end not earlier than 2013 (or 2014 for France and Italy). Our results are in line with a well-established literature strand (see, e.g., Becker and Ivashina, 2014; Xie, 2016; Bher et al., 2017), which shows that credit growth follows a procyclical pattern: in an economic upturn credit is booming, while in a downturn with a gloomy outlook bank credit shrinks. Results are also backed by the studies of Fernandez et al. (2013), and Behn et al. (2016), which document a significant reduction in credit supply as a result of a systemic financial crisis that exerts an exogenous shock to the bank credit channel. Overall, we provide strong empirical support to the positive link between the degree of competition and bank business loans, which we have postulated in our theoretical analysis. Notably, this link has been broadly documented in the literature. For example, as argued in Andres et al. (2013), when competition increases, the lending spreads fall implying that credit turns to be cheaper and hence entrepreneurs become more leveraged.

The analysis of the mean values of $N P L$ offers evidence that competition gives rise to higher credit risk, which materialises immediately after the eruption of the crisis. More concretely, $N P L$ remains relatively stable showing only some minor upward and downward fluctuations over the years 2000 to 2006. In 2007, NPL precipitously increases, adding to banks' risk exposure and undermining financial stability. Hence, loans to riskier entrepreneurs in the pre-crisis period due to higher competition and also due to the lower lending rates incur a higher NPL ratio because risks materialise during the economic downturn. Accordingly, we provide strong support to our theoretical findings that suggest a positive link between competition and loan portfolio risk. This result is consistent with the traditional competition-fragility view of Keeley (1990) according to which increasing competition reduces the loan quality of banks. The view that a more competitive market leads financial institutions to take on riskier lending decisions in a race to the bottom is fairly grounded in the previous theoretical (e.g., Hellmann et al., 2000; Matutes and 
Vives, 2000; Gomez and Ponce, 2014), and empirical literature (e.g., Berger et al., 2009; Jiménez et al., 2013; Kabir and Worthington, 2017; Leroy and Lucotte, 2017).

We resort to $t$-statistics to test the significance of the mean differences we report in our variables between the pre- and the post-crisis periods for each of the G7 economies. The differences are found to be statistically significant either at the $1 \%$ or $5 \%$ levels for all four variables under scrutiny. ${ }^{13}$ On the whole, the empirical analysis we conduct provides robust support to our theoretical modelling environment and to the obtained theoretical findings.

\section{Conclusions}

A highly contentious relationship in the banking literature is that between market structure, lending behaviour, screening, and credit risk. Notwithstanding the substantial changes in the banking market which have been lately occurred, very few recent studies focus on this relationship. We elaborate on this literature gap by developing a theoretical model that examines the impact of changes in the market structure on the lending behaviour of banks as well as on the screening technology that banks use to soften the information problem they are faced with and, in turn, on the level of credit risk.

Our results provide support to the view that greater competition reduces lending cost. Hence, a bank that offers cheaper credit can poach customers from its competitors thus gaining a substantial share in the market. Notably, the power of this finding is not restricted in the neighbourhood of the less expensive banks, implying that the transportation cost plays no role in the decision of applicants to travel to (move away from) a bank that decreases (increases) its lending rates. What is enlightening in our findings is that competition exerts a decreasing effect on the price of credit for all types of borrowers in our model, that is, for both good and bad ones. Therefore, it can be inferred that enhanced competition has an increasing impact on the level of credit risk. Interestingly, this finding holds true regardless of whether or not a bank enhances its share in the loan market.

By taking a holistic view of these results, we can claim that competition exerts a downward impact on the equilibrium loan rates, while at the same time it makes it easier for potential borrowers to travel to the bank that satisfies their type as it reduces transportation cost. This

\footnotetext{
${ }^{13}$ The results are available upon request.
} 
reduction in the total cost of credit favours the access of an increased number of borrowers to the loan market, but also triggers an increase in credit risk.

Moreover, we show that, by investing in screening, a bank can effectively distinguish good from bad investment projects and, as a consequence, the quality of its portfolio can be improved. Importantly, banks are found to invest more in screening as a result of fiercer competition. An explanation is that banks are more easily mistaken in their lending decisions as the number of applicants increase due to enhanced competition. By dealing with a larger number of applicants and, therefore, with a greater portion of bad applicants who incur higher credit risk, banks are induced to step up screening.

Overall, we provide strong theoretical evidence which is supported by our empirical analysis of a clear link between market structure, bank lending, screening, and the risk-taking behaviour of banks. When market conditions are distorted as has been the case with the global financial crisis, this has a dilutive impact on the incentives mechanism of banks to screen their applicants. We acknowledge, however, that factors other than changes in the market structure may also have an influence on banks' screening incentives. For example, various studies (see, e.g., Mian and Sufi, 2009; Keys et al., 2010) provide evidence that banks relaxed their screening and monitoring standards in the sub-prime mortgage market prior to the crisis mostly due to the opaqueness of securitisation. An investigation of the relevance of these as well as other factors like loan composition, bank size, ownership structure, to name but a few, is out of the scope of this paper and, as such, can be considered for future research.

\section{Acknowledgements}

I would like to thank the Organising Committee of the FINEST/AIDEA Conference 2013 held in Lecce (Italy) for awarding the paper with the Best Paper Award. I also thank the participants in the $27^{\text {th }}$ Symposium on Money, Banking, and Finance, the $17^{\text {th }}$ Annual Conference of the Multinational Finance Society, and the PortsmouthFordham Conference on Banking and Finance for their valuable comments and suggestions. The paper has benefited from insightful discussions with Michel Dietsch, Franco Fiordelisi, Iftekhar Hasan, Robert Kreiner, Joël Petey, Daniele Angelo Previati, and Maria Gaia Soana. The author would like to express his sincere thanks to the two anonymous reviewers, the Associated Editor, and the Editor of the European Journal of Finance, Chris Adcock, for their incisive comments. Special thanks are extended to Shelly Anne Stringer and also to an anonymous Senior Advisor of the Bournemouth University Writing Academy for their professional assistance in proofreading the paper. 


\section{References}

Acharya, V.V., I. Hasan, and A. Saunders. 2006. "Should Banks be Diversified? Evidence from Individual Bank Loan Portfolios.” Journal of Business 79 (3): 1355-1412.

Agarwal, S., and R. Hauswald. 2010. "Distance and Private Information in Lending." The Review of Financial Studies 23 (7): 2757-2788.

Akins, B., L. LI, J. Ng, and T.O. Rusticus. 2016. "Bank Competition and Financial Stability: Evidence from the Financial Crisis." Journal of Quantitative Analysis 51 (1): 1-28.

Andres, J., O. Arce, and C. Thomas. 2013. "Banking Competition, Collateral Constraints, and Optimal Monetary Policy.” Journal of Money, Credit, and Banking 45 (2): 87-125.

Baggs, J., and J.-E. de Bettignies. 2007. "Product Market Competition and Agency Costs". Journal of Industrial Economics 55 (2): 289-323.

Bain, J.S. 1951. "Relation of Profit Rate to Industry Concentration: American Manufacturing, 1936-1940.” Quarterly Journal of Economics 65 (3): 293-324.

Beck, T., O. De Jonghe, and G. Schepens. 2013. "Bank Competition and Stability: CrossCountry Heterogeneity." Journal of Financial Intermediation 22 (2): 218-244.

Becker, B., and V. Ivashina. 2014. “Cyclicality of Credit Supply: Firm Level Evidence.” Journal of Monetary Economics 62: 76-93.

Behr, P., D. Foos, and L. Norden. 2017. "Cyclicality of SME Lending and Government Involvement in Banks.” Journal of Banking and Finance 77: 64-77.

Behn, M., H. Rainer, and P. Wachtel, 2016, "Procyclical Capital Regulation and Lending." Journal of Finance 71 (2): 919-956.

Berger, A.N., and T.H. Hannan. 1989. "The Price-Concentration Relationship in Banking." Review of Economics and Statistics 71 (2): 291-99.

Berger, A.N., L.F. Klapper, and R. Turk-Ariss, 2009. "Bank Competition and Financial Stability." Journal of Financial Services Research 35 (2): 99-118.

Berger, A., and R. Roman. 2015. "Did TARP Banks Get Competitive Advantages?" Journal of Financial and Quantitative Analysis 50 (6): 1199-1236.

Bolton, P., X. Freixas, L. Gambacorta, and P.E. Mistrulli. 2013. Relationship and Transaction Lending in a Crisis. Bank for International Settlements Working Papers no 417.

Boot, A.W.A, and A.V. Thakor. 2000. "Can Relationship Banking Survive Competition?" Journal of Finance 55 (2): 679-713. 
Bose, A., P. Debashis, and D.E.M. Saapington. 2012. "Extreme Screening Policies." European Economic Review 56 (8): 1607-1620.

Bouckaert, J., and H. Degryse. 2006. "Entry and Strategic Information Display in Credit Markets." Economic Journal 116 (513): 702-720.

Boyd, J.H., and G. De Nicolò. 2005. "The Theory of Bank Risk Taking and Competition Revisited." Journal of Finance 60 (3): 1329-1343.

Broecker, T. 1990. "Creditworthiness Tests and Interbank Competition." Econometrica 58 (2): 429-452.

Caglayan, M., and B. Xu. 2016. "Inflation Volatility Effects on the Allocation of Bank Loans." Journal of Financial Stability 24: 27-39.

Cao, M., and S. Shi. 2001. "Screening Bidding and the Loan Market Tightness." European Finance Review 5 (1-2): 21-61.

Cetorelli N., and P.F. Peretto. 2000. Oligopoly Banking and Capital Accumulation. Federal Reserve Bank of Chicago Working Paper Series WP/00/12.

Chiappori, P.A., D. Perez-Castrillo, and F. Verdier. 1995. "Spatial Competition in the Banking System, Localisation, Cross-subsidies and the Regulation of Interest Rates." European Economic Review 39 (5): 889-918.

Chronopoulos, D.K., H. Liu, F.J. McMillan, and J.O.S. Wilson. 2015. "The dynamics of US bank profitability." European Journal of Finance 21 (5): 426-443.

Claessens, S., and L. Laeven. 2004. "What Drives Bank Competition? Some International Evidence." Journal of Money, Credit and Banking 36 (3): 563-583.

Davis, P. 2006. "Measuring the Business Stealing, Cannibalization, and Market Expansion Effects of Entry in the U.S. Motion Picture Exhibition Market." Journal of Industrial Economics 54 (3): 293-321.

De Guevara, J.F., J. Maudos, and F. Perez, 2005. "Market Power in the European Banking Sector." Journal of Financial Services Research 27 (2): 109-137.

De Nicolò, G., and E. Loukoianova. 2007. Bank Ownership, Market Structure and Risk. IMF Working Paper WP/07/215.

Degryse, H., and S. Ongena. 2005. "Distance, Lending Relationships and Competition.” Journal of Finance 60 (1): 231-266. 
Dell'Ariccia, G. 2000. Learning by Lending, Competition, and Screening Incentives in the Banking Industry. IMF mimeo.

Dell'Ariccia, G. 2001. "Asymmetric Information and the Structure of the Banking Industry." European Economic Review 45 (10): 1957-1980.

Dell' Ariccia, G., and R. Marquez. 2004. "Information and Bank Credit Allocation." Journal of Financial Economics 72 (1): 185-214.

Fernández, A.I., F. González, and N. Suárez. 2013. "How do Bank Competition, Regulation, and Institutions Shape the Real Effect of Banking Crises? International Evidence." Journal of International Money and Finance 33: 19-40.

Freixas, X., S. Hurkens, A. Morrison, and N. Vulkan. 2007. "Interbank Competition with Costly Screening." BE Journal of Theoretical Economics 7 (1): 1-25.

Gehrig, T. 1998. "Screening, Cross-border Banking, and the Allocation of Credit." Research in Economics 52 (4): 387-407.

Gehrig, T., and R. Stenbacka. 2011. "Decentralized Screening: Coordination Failure, Multiple Equilibria and Cycles." Journal of Financial Stability 7: 60-69.

Gomez, F., and J. Ponce. 2014. "Bank Competition and Loan Quality." Journal of Financial Services Research 46 (3): 215-233.

Hainz, C., L. Weill, and C.J. Godlewski. 2013. "Bank Competition and Collateral: Theory and Evidence." Journal of Financial Services Research 44 (2): 1185-1222.

Hakenes, H., and I. Schnabel. 2010. "Banks without Parachutes: Competitive Effects of Government Bail-out Policies.” Journal of Financial Stability 6: 156-168.

Hauswald, R., and R. Marquez. 2006. "Competition and Strategic Information Acquisition in Credit Markets." The Review of Financial Studies 19 (3): 967-1000.

Hotelling, H. 1929. “Stability in Competition.” Economic Journal 39 (153): 41-57.

Hyytinen, A. 2003. "Information Production and Lending Market Competition." Journal of Economic and Business 55 (3): 233-253.

Jimenez, G., J.A. Lopez, and J. Saurina. 2013. "How does Competition Affect Bank RiskTaking?" Journal of Financial Stability 9: 185-195.

Kabir, M.N., and A.C. Worthington. 2017. "The 'Competition-Stability/Fragility' Nexus: A Comparative Analysis of Islamic and Conventional Banks." International Review of Financial Analysis 50: 111-128. 
Karapetyan, A., and B. Stacescu. 2014. "Does Information Sharing Reduce the Role of Collateral as a Screening Device?" Journal of Banking and Finance 43: 48-57.

Keeley, M. 1990. “Deposit Insurance, Risk, and Market Power in Banking.” American Economic Review 80 (5): 1183-1200.

Keys, B.J., T. Mukherjee, A. Seru, and V. Vig. 2010. "Did Securitization Lead to Lax Screening? Evidence from Subprime Loans.” Quarterly Journal of Economics 125 (1): 307362.

Khan, H.H., R.B. Ahmad, and S.G. Chan. 2018. "Market Structure, Bank Conduct and Bank Performance: Evidence from ASEAN.” Journal of Policy Modelling, forthcoming.

Kick, T., and E. Prieto. 2015. "Bank Risk and Competition: Evidence from Regional Banking Markets." Review of Finance 19 (3): 1-38.

Koetter, M., and N. Felix. 2016. "Did TARP Distort Competition Among Sound Unsupported Banks?”. Economic Inquiry 54 (2): 994-1020.

Laeven, L., and G. Majnoni. 2003. "Loan Loss Provisioning and Economic Slowdowns: Too Much, Too Late?” Journal of Financial Intermediation 12 (2): 178-197.

Lehner, M., and M. Schnitzer. 2008. "Entry of Foreign Banks and Their Impact on Host Countries.” Journal of Comparative Economics 36 (3): 430-452.

Leroy, A., and Y. Lucotte. 2017. "Is There a Competition-Stability Trade-Off in European Banking?” Journal of International Financial Markets, Institutions, and Money 46: 199-215.

Mankiw, N.G., and M.D. Whinston. 1986. "Free Entry and Social Inefficiency." Rand Journal of Economics 17 (1): 48-58.

Manove, M.A., J. Padilla, and M. Pagano. 2001. “Collateral Versus Project Screening: A Model of Lazy Banks.” Rand Journal of Economics 32 (4): 726-744.

Marquez, R. 2002. "Competition, Adverse Selection, and Information Dispersion in the Banking Industry," The Review of Financial Studies 15 (3): 901-926.

Mian, A., and A. Sufi. 2009. "The Consequences of Mortgage Credit Expansion: Evidence from the 2007 Mortgage Default Crisis.” Quarterly Journal of Economics 124 (4): 1449-1496.

Neumark, D., and S.A. Sharpe. 1992. "Market Structure and the Nature of Price Rigidity: Evidence from the Market for Consumer Deposits." Quarterly Journal of Economics 107 (2): 657-80. 
Panzar, J.C., and J.N. Rosse. 1987. “Testing for 'Monopoly' Equilibrium.” Journal of Industrial Economics 35 (4): 443-456.

Pennacchi, G. 2018. “Banks, Taxes, and Nonbank Competition.” Journal of Financial Services Research, forthcoming.

Pérez Montes, C. 2014. "The Effect on Competition of Banking Sector Consolidation Following the Financial Crisis of 2008." Journal of Banking and Finance 43: 124-136.

Petersen, M., and R. Rajan. 2002. "Does Distance Still Matter? The Information Revolution in Small Business Lending.” Journal of Finance 57 (6): 2533-2570.

Pool, S., L. de Haan, and J.P.A.M. Jacobs. 2015. "Loan Loss Provisioning, Bank Credit, and the Real Economy." Journal of Macroeconomics 45: 124-136.

Raith, M. 2003. "Competition, Risk, and Managerial Incentives.” American Economic Review 93 (4): 1425-1436.

Sääskilahti, J. 2016. "Local Bank Competition and Small Business Lending After the Onset of the Financial Crisis.” Journal of Banking and Finance 69: 37-51.

Salop, S.C. 1979. "Monopolistic Competition with Outside Goods.” Bell Journal of Economics 10 (1): 141-156.

Schaeck, K., M. Cihak. 2012. "Banking Competition and Capital Ratios.” European Financial Management 18 (5): 836-866.

Schaeck, K., M. Cihak, and S. Wolfe. 2009. “Are Competitive Banking Systems More Stable?" Journal of Money, Credit and Banking 41 (4): 711-734.

Schnitzer, M. 1999. "Enterprise Restructuring and Bank Competition in Transition Economies." Economics of Transition 7 (1): 133-155.

Shaffer, S. 1998. "The Winner's Curse in Banking.” Journal of Financial Intermediation 7 (4): 359-392.

Soedarmono, W., F. Machrouh, and A. Tarazi. 2013. "Bank Competition, Crisis and Risk Taking: Evidence from Emerging Markets in Asia." Journal of International Financial Markets, Institutions, and Money 23: 196-221.

Villas-Boas, J.M., and U. Schmidt-Mohr. 1999. "Oligopoly with Asymmetric Information: Differentiation in Credit Markets.” The RAND Journal of Economics 30 (3): 375-396. 
Williams, J., and N. Nguyen, N. 2005. "Financial Liberalisation, Crisis, and Restructuring: A Comparative Study of Bank Performance and Bank Governance in South East Asia." Journal of Banking and Finance 29: 2119-2154.

Xie, B. 2016. "Does Fair Value Accounting Exacerbate the Procyclicality of Banking Lending?" Journal of Accounting Research 54 (1): 235-274. 


\section{Appendix A}

This Appendix describes in detail how the symmetric price equilibrium is obtained.

Eq. (9) can be written as follows:

$$
\begin{aligned}
& \max _{r_{h}^{j}, r_{l}^{j}} \pi^{j}= \frac{q p_{h} r_{h}^{j}}{n}+\frac{q p_{h}^{2} r_{h}^{j} r_{h}^{j+1}-q p_{h}^{2}\left(r_{h}^{j}\right)^{2}}{\tau_{h}}-\frac{1}{n}-\frac{p_{h} r_{h}^{j+1}-p_{h} r_{h}^{j}}{\tau_{h}}- \\
&-\frac{e}{n}-\frac{e p_{h} r_{h}^{j+1}+e p_{h} r_{h}^{j}}{\tau_{h}}+\frac{p_{l} r_{l}^{j}}{n}+\frac{p_{l}^{2} r_{l}^{j} r_{l}^{j+1}-p_{l}^{2}\left(r_{l}^{j}\right)^{2}}{\tau_{l}}- \\
&-\frac{q p_{l} r_{l}^{j}}{n}-\frac{q p_{l}^{2} r_{l}^{j} r_{l}^{j+1}+q p_{l}^{2}\left(r_{l}^{j}\right)^{2}}{\tau_{l}}-\frac{1}{n}-\frac{p_{l} r_{l}^{j+1}+p_{l} r_{l}^{j}}{\tau_{l}}- \\
&-\frac{e}{n}-\frac{e p_{l} r_{l}^{j+1}+e p_{l} r_{l}^{j}}{\tau_{l}}
\end{aligned}
$$

To obtain bank $j$ 's optimal loan interest rate for the $h$-type borrowers, we calculate the first order conditions of (A1) with respect to $r_{h}^{j}$ :

$$
\begin{aligned}
\frac{\partial \pi^{j}\left(r^{j}, r^{j+1}\right)}{\partial r_{h}^{j}}=0 & \Rightarrow \frac{q p_{h}}{n}+\frac{q p_{h}^{2} r_{h}^{j+1}-2 q p_{h}^{2} r_{h}^{j}}{\tau_{h}}+\frac{p_{h}}{\tau_{h}}+\frac{e p_{h}}{\tau_{h}}=0 \Leftrightarrow \\
& \Leftrightarrow \tau_{h} q+n q p_{h} r_{h}^{j+1}-2 n q p_{h} r_{h}^{j}+n+n e=0
\end{aligned}
$$

To obtain the symmetric Nash equilibrium, we set $r_{h}^{j}=r_{h}^{j+1}$ :

$$
n q p_{h} r_{h}^{j}=\tau_{h} q+n(1+e) \Leftrightarrow r_{h}^{j}=\frac{\tau_{h}}{n p_{h}}+\frac{(1+e)}{q p_{h}} \Leftrightarrow r_{h}^{j}=\frac{1}{p_{h}}\left[\frac{\tau_{h}}{n}+\frac{(1+e)}{q}\right]
$$

We work in a similar way to get the optimal loan rate for the $l$-type borrowers:

$$
\begin{aligned}
\frac{\partial \pi^{j}\left(r^{j}, r^{j+1}\right)}{\partial r_{l}^{j}}=0 & \Rightarrow \frac{p_{l}}{n}+\frac{p_{l}^{2} r_{l}^{j+1}-2 p_{l}^{2} r_{l}^{j}}{\tau_{l}}-\frac{q p_{l}}{n}-\frac{q p_{l}^{2} r_{l}^{j+1}+2 q p_{l}^{2} r_{l}^{j}}{\tau_{l}}+\frac{p_{l}}{\tau_{l}}+\frac{e p_{l}}{\tau_{l}}=0 \Leftrightarrow \\
& \Leftrightarrow \tau_{l}+n p_{l} r_{l}^{j+1}-2 n p_{l} r_{l}^{j}-\tau_{l} q-n q p_{l} r_{l}^{j+1}+2 n q p_{l} r_{l}^{j}+n+n e=0
\end{aligned}
$$


We now set $r_{l}^{j}=r_{l}^{j+1}$ :

$$
n p_{l} r_{l}^{j}-n q p_{l} r_{l}^{j}=\tau_{l}(1-q)+n(1+e) \Leftrightarrow r_{l}^{j}=\frac{t_{l}}{n p_{l}}+\frac{(1+e)}{p_{l}(1-q)} \Leftrightarrow r_{l}^{j}=\frac{1}{p_{l}}\left[\frac{\tau_{l}}{n}+\frac{(1+e)}{(1-q)}\right]
$$

\section{Appendix B}

This Appendix describes the calculation of $H$-Statistic. We follow Claessens and Laeven (2004), Schaeck et al. (2009), and Schaeck and Cihak (2012) to estimate the reduced form revenue equation for each of the seven sample economies using bank- and year-level observations:

$$
\begin{aligned}
\ln \left(T R_{j t c}\right)= & a+\beta_{1} \ln \left(w_{1, j t c}\right)+\beta_{2} \ln \left(w_{2, j t c}\right)+\beta_{3} \ln \left(w_{3, j t c}\right)+\gamma_{1} \ln \left(y_{1, j t c}\right) \\
& +\gamma_{2} \ln \left(y_{2, j t c}\right)+\gamma_{3} \ln \left(y_{3, j t c}\right)+\varepsilon_{j t c}
\end{aligned}
$$

where $T R$ stands for the total interest revenue from loans divided by total assets (output price); $w_{1}$ is the ratio of interest expenses to total deposits (input price of deposits); $w_{2}$ is the ratio of personnel expenses to total assets (input price of labour); $w_{3}$ is the ratio of other operating

expenses to total assets (input price of fixed assets); $y_{1}$ stands for the ratio of total deposits to total debt; $y_{2}$ is the ratio of total loans to total earning assets; and $y_{3}$ is the ratio of total equity to total assets.

We calculate the $H$-Statistic by estimating the sum of elasticities of the reduced form revenue equation with respect to the input prices:

$$
H_{t c}=\sum_{m=1}^{3} \frac{\partial T R_{i t c}^{*}}{\partial w_{m_{i}}} \frac{w_{m_{i}}}{R_{i t c}^{*}}
$$

